Известия вузов России. Радиоэлектроника. 2021. Т. 24, № 2. С. 27-37

Journal of the Russian Universities. Radioelectronics. 2021, vol. 24, no. 2, pp. 27-37

Radar and Navigation

UDC 621.396 .96

Original article

https://doi.org/10.32603/1993-8985-2021-24-2-27-37

\title{
A Simple Algorithm for Compensation for Range Cell Migration in a Stripmap SAR
}

\author{
Andrey A. Monakov ${ }^{凶}$ \\ Saint Petersburg State University of Aerospace Instrumentation (SUAI), \\ St Petersburg, Russia \\ 凶a_monakov@mail.ru
}

\begin{abstract}
Introduction. Range Cell Migration (RCM) is a source of image blurring in synthetic aperture radars (SAR). There are two groups of signal processing algorithms used to compensate for migration effects. The first group includes algorithms that recalculate the SAR signal from the "along-track range - slant range" coordinate system into the "along-track range - cross-track range" coordinates using the method of interpolation. The disadvantage of these algorithms is their considerable computational cost. Algorithms of the second group do not rely on interpolation thus being more attractive in terms of practical application.

Aim. To synthesize a simple algorithm for compensating for RCM without using interpolation.

Materials and methods. The synthesis was performed using a simplified version of the Chirp Scaling algorithm. Results. A simple algorithm, which presents a modification of the Keystone Transform algorithm, was synthesized. The synthesized algorithm based on Fast Fourier Transforms and the Hadamard matrix products does not require interpolation.

Conclusion. A verification of the algorithm quality via mathematical simulation confirmed its high efficiency. Implementation of the algorithm permits the number of computational operations to be reduced. The final radar image produced using the proposed algorithm is built in the true Cartesian coordinates. The algorithm can be applied for SAR imaging of moving targets. The conducted analysis showed that the algorithm yields the image of a moving target provided that the coherent processing interval is sufficiently large. The image lies along a line, which angle of inclination is proportional to the projection of the target relative velocity on the line-of-sight. Estimation of the image parameters permits the target movement parameters to be determined.
\end{abstract}

Keywords: synthetic aperture radar (SAR), range cell migration, keystone transform, chirp scaling

For citation: Monakov A. A. A Simple Algorithm for Compensation of the Range Cell Migration in a Stripmap SAR. Journal of the Russian Universities. Radioelectronics. 2021, vol. 24, no. 2, pp. 27-37. doi: 10.32603/1993-89852021-24-2-27-37

Conflict of interest. The author declares no conflict of interest.

Submitted 01.12.2020; accepted 25.01.2021; published online 29.04.2021 
Известия вузов России. Радиоэлектроника. 2021. Т. 24, № 2. С. 27-37

Journal of the Russian Universities. Radioelectronics. 2021, vol. 24, no. 2, pp. 27-37

Радиолокация и радионавигация

Оригинальная статья

\title{
Простой алгоритм компенсации миграций светящихся точек по дальности для режима бокового обзора РСА
}

\author{
А. А. Монаков ${ }^{\bowtie}$ \\ Санкт-Петербургский государственный университет \\ аэрокосмического приборостроения (ГУАП), Санкт-Петербург, Россия \\ a_monakov@mail.ru
}

\section{Аннотация}

Введение. Миграции светящихся точек по дальности являются источником расфокусировки радиолокационных изображений в радиолокаторах с синтезированной апертурой (РСА). Существует две группы алгоритмов обработки сигналов для компенсации миграций. Первая группа включает алгоритмы, в которых на основании методов функциональной интерполяции осуществляется пересчет принятых сигналов из системы координат "продольная дальность - наклонная дальность" в систему "продольная дальность - поперечная дальность". Недостатком алгоритмов данной группы является их высокая вычислительная сложность. Алгоритмы второй группы не используют интерполяционные методы и являются поэтому более привлекательными для практического использования.

Цель. Синтезировать простой алгоритм компенсации миграций без применения функциональной интерполяции. Материалы и методы. Синтез алгоритма осуществлен на основании упрощенной версии алгоритма ЛЧМфильтрации (Chirp Scaling Algorithm).

Результаты. Синтезирован простой алгоритм, являющийся модификацией алгоритма "замкового камня". Алгоритм основан на использовании быстрых преобразований Фурье и поэлементных матричных умножений. В алгоритме не применяются методы интерполяции.

Заключение. Проверка качества алгоритма на основе математического моделирования подтвердила его высокую эффективность. Использование алгоритма позволяет уменьшить количество вычислительных операций. Финальное радиолокационное изображение, получаемое с помощью алгоритма, строится в истинной декартовой системе координат. Алгоритм может быть применен для построения РСА изображений движущихся целей. Данный в статье анализ показал, что алгоритм позволяет построить хорошо сфокусированное изображение движущейся цели, когда интервал синтезирования достаточно велик. Изображение движущейся цели выстраивается вдоль отрезка прямой, угол наклона которой пропорционален проекции относительной скорости цели на линию визирования. Оценка параметров изображения позволяет определить параметры движения цели.

Ключевые слова: радар с синтезированной апертурой (РСА), миграции светящихся точек по дальности, преобразование "замкового камня", ЛЧМ-фильтрация

Для цитирования: Монаков А. А. Простой алгоритм компенсации миграций светящихся точек по дальности для режима бокового обзора РСА// Изв. вузов России. Радиоэлектроника. 2021. Т. 24, № 2. С. 27-37. doi: 10.32603/1993-8985-2021-24-2-27-37

Конфликт интересов. Автор заявляет об отсутствии конфликта интересов.

Статья поступила в редакцию 01.12.2020; принята к публикации после рецензирования 25.01.2021; опубликована онлайн 29.04.2021

Introduction. The Range Cell Migration (RMC) takes place in synthetic aperture radar (SAR) of high range resolution due to the range walk of the compressed signal through range resolution cells. The RCM causes significant image blurring [1, 2]. Nowadays there are a number of signal processing algorithms to compensate for its negative influence on the SAR image quality. These algorithms can be subdi-vided into two groups. Algorithms of the first group use the function interpolation. The SAR 2D signal matrix undergoes the transformation from the "along-track range - slant range" coordinate system to the "along-track range - cross-track range" system. The Range - Doppler Algorithm [3-6], the Wave Number Algorithm [7-10] and the Keystone Transform (KT) [11, 12] belong to this group. When 
the received signal matrix is large, the nonlinear transformation from the first coordinate system to the second one is a burdensome computational problem that requires significant computing power. Besides, the interpolation can cause the appearance of spurious targets in SAR images. Algorithms of the second group do not implement the interpolation and, in this sense, they are more attractive for implementation. The Chirp Scaling Algorithm [13-17], the Extended Chirp Scaling Algorithm [18] and the Frequency Scaling Algorithm [19, 20] are in this group. Quality of algorithms of the second group is not worse, but they are faster due to the Fast Fourier Transforms (FFT) used for their realization.

The KT, which was firstly introduced in [11], occupies a special position among algorithms of the first group because it can be adopted for SAR imaging of moving targets [12]. Extension of the KT for the moving target imaging is based on the assumption that the range curvature is not large during the coherent processing interval and the range walk can be considered only velocity-based (linear). The success of the algorithm gave rise to additional search of efficient signal processing algorithms to compensate for the RMC. In [21] the second order KT algorithm was suggested especially for the moving target imaging. This algorithm permits to compensate the range walk in case of large range curvature. In [22] the second order double-Keystone Transform is presented. This algorithm can correct for both velocity-based and acceleration-based (quadrature) range walk.

Later the KT without interpolation, which is named the ZLZ-algorithm in the paper using the first letters of the authors' names, was proposed in [23]. The Chirp Scaling (CS) developed in [24] is used in this algorithm to avoid the interpolation. The algorithm combines the KT simplicity with a high efficiency of the CS. Although this algorithm was synthesized to compensate for the linear component of the range walk for the moving target, it can be used for SAR imaging of stationary targets too.

In this paper the synthesis and the analysis of a new algorithm to compensate for the RCM in a stripmap SAR are presented. The algorithm is based on a reduced version of the CS to get rid of the interpolation. The algorithm is computationally simpler than the ZLZ-algorithm and has the same image quality.
In case of stationary target imaging the final radar image is built in the "along-track range - cross-track range" coordinate system, thus avoiding geometrical distortions that appear in the image constructed in the "along-track range - slant range" coordinates by the ZLZ-algorithm. Analysis of moving target imaging of the algorithms is performed in the paper using the approach firstly implemented in [25] and based on the theory of distributions (generalized functions). It is proved that the proposed algorithm and the ZLZ-algorithm yield different radar images of a moving target. Particularly the image produced by the proposed algorithm has a noticeable inclination in the "along-track range - cross-range range" coordinate plane and the inclination angle depends to the projection of the target relative velocity on the target line-of-sight.

Development of the algorithm. Let us suppose the transmitted signal is a wideband pulse with the spectrum $S(\omega)$ uniform in the frequency band $[-\pi \Delta F, \pi \Delta F]$. Neglecting a time delay in the matched filter, the output signal spectrum is $A(\omega)=|S(\omega)|^{2}$. All calculation in the paper are performed in a 2D Cartesian coordinate system $\mathrm{XOY}$, which is stationary relating the SAR vehicle. The $X$ axis is directed along the vehicle velocity $\mathbf{V}$, and the $Y$ axis looks along the antenna beam. Then the signal received from a surface point $\left(x_{0}, y_{0}\right)$ is

$$
s s(t, \tau)=a\left(\tau-\frac{2 R(t)}{c}\right) \exp \left[-i k_{0} R(t)\right]
$$

where $a(\tau)=(2 \pi)^{-1} \int A(\omega) e^{i \omega \tau} d \omega$ is a complex envelop of the pulse at the output of the matched filter; $\tau \in\left[0, T_{r}\right]$ is the "fast" time; $t \in\left[0, T_{a}\right]$ is the "slow" time; $T_{r}$ is a pulse repetition interval; $T_{a}$ is a coherent processing interval (CPI);

$$
R(t)=\sqrt{\left(x_{0}-v t\right)^{2}+y_{0}^{2}}
$$

is the slant range of the point; $v=|\mathbf{V}|$ is the vehicle speed; $c$ is the speed of light; $k_{0}=\frac{2 \omega_{0}}{c}=\frac{4 \pi}{\lambda_{0}}$ is the wave number $\left(\omega_{0}\right.$ and $\lambda_{0}$ are the carrier frequency 
Известия вузов России. Радиоэлектроника. 2021. Т. 24, № 2. С. 27-37

Journal of the Russian Universities. Radioelectronics. 2021, vol. 24, no. 2, pp. 27-37

and the wavelength correspondingly). For further calculations it is more convenient to represent the 2D signal $s s(t, \tau)$ in coordinates "along-track range - crosstrack range":

$$
s s(x, y)=a[y-R(x)] \exp \left[-i k_{0} R(x)\right],
$$

where $x=v t \in\left[0, v T_{a}\right]$ is the along-track range; $y=c \tau \in\left[0, c T_{r}\right]$ is the cross-track range; $R(x)=\sqrt{\left(x_{0}-x\right)^{2}+y_{0}^{2}}$.

The direct Fourier transform of signal (1) over $y$ is

$$
\begin{aligned}
& s S(x, k)=\int s s(x, y) e^{-i k y} d y= \\
& =A(k) \exp \left[-i\left(k_{0}+k\right) R(x)\right],
\end{aligned}
$$

where $k=\frac{2 \omega}{c}$ is the range wavenumber corresponding to the spectral frequency $\omega ; A(k)=A(\omega)_{\omega=c k / 2}$ is the spectrum of the signal complex envelop $a(t)$ written as a function of $k$.

Let us suppose that the cross-track range of the point is much larger than the length of the CPI, i. e. $y_{0} \gg v T_{a}$. Then the following equation is true for the slant range:

$$
R(x)=R_{0}+R_{0}^{\prime}+\frac{1}{2} R_{0}^{\prime \prime} x^{2},
$$

where $R_{0}=R(0), R_{0}^{\prime}=R^{\prime}(0), R_{0}^{\prime \prime}=R^{\prime \prime}(0)$ are the values of $R(x)$ and its first two derivatives in the point $x=0$. Equation (2) can be rewritten as,

$$
\begin{gathered}
s S(x, k)=A(k) e^{-i\left(k_{0}+k\right) R_{0}} \times \\
\times \exp \left[-i\left(k_{0}+k\right)\left(R_{0}^{\prime} x+\frac{1}{2} R_{0}^{\prime \prime} x^{2}\right)\right] .
\end{gathered}
$$

Presence of $k$ in the argument of the second exponent in (3) is a result of the RCM. Transition to a new along-track range

$$
x^{\prime}=\frac{k_{0}+k}{k_{0}} x,
$$

permits to factorize phasors of $s S(x, k)$ depending on the range wavenumber $k$ and the along-track range $x$. In the KT-algorithm transition (4) is performed via the function interpolation, and in this way the RCM compensation is realized.
Translation (4) is a scale transform. To perform it without interpolation let us use the following identity:

$$
\begin{gathered}
\exp \left[-i \alpha x^{2}\right] \otimes \exp \left[-i \beta x^{2}\right]= \\
=C \exp \left[-i \frac{\alpha \beta}{\alpha+\beta} x^{2}\right],
\end{gathered}
$$

where $\alpha$ and $\beta$ are arbitrary scalars, $\otimes$ is the convolution operator. The constant $C=C(\alpha, \beta)$ depends on $\alpha$ and $\beta$, but does not depend on the variable $x$.

Let $\alpha=\frac{1}{2}\left(k_{0}+k\right) R_{0}^{\prime \prime}$ and $\gamma=\frac{\alpha \beta}{\alpha+\beta}=\frac{1}{2} k_{0} R_{0}^{\prime \prime}$, then

$$
\beta=\frac{\alpha \gamma}{\alpha-\gamma}=\frac{R_{0}^{\prime \prime}}{2}\left(\frac{1}{k_{0}}-\frac{1}{k_{0}+k}\right)^{-1} .
$$

Thus, the convolution of $s S(x, k)$ with the function

$$
h_{1}(x, k)=\exp \left[-\frac{R_{0}^{\prime \prime} x^{2}}{2}\left(\frac{1}{k_{0}}-\frac{1}{k_{0}+k}\right)^{-1}\right]
$$

yields the desired scale transform. This convolution can be done in the azimuth wavenumber domain, if one takes into account that the direct Fourier transforms of $s S(x, k)$ and $h_{1}(x, k)$ over the along-track range $x$ are:

$$
\begin{gathered}
S S(K, k)=\int s S(x, k) e^{-i K x} d x= \\
=C_{1} A(k) e^{-i\left(k_{0}+k\right) R_{0}} e^{-i K x_{0}} \exp \left\{\frac{\left[K+\left(k_{0}+k\right) R_{0}^{\prime}\right]^{2}}{2\left(k_{0}+k\right) R_{0}^{\prime \prime}}\right\} \\
H_{1}(K, k)=\int h_{1}(x, k) e^{-i K x} d x= \\
=C_{2} \exp \left[\frac{K^{2}}{2 R_{0}^{\prime \prime}}\left(\frac{1}{k_{0}}-\frac{1}{k_{0}+k}\right)\right]
\end{gathered}
$$

where $C_{1}$ and $C_{2}$ are constants independent on the range and azimuth wavenumbers $k$ and $K$.

It is easy to prove that the product

$$
\begin{gathered}
S S_{1}(K, k)=S S(K, k) H_{1}(K, k)= \\
=C A(k) \exp \left[-i\left(k_{0}+k\right)\left(R_{0}-\frac{R_{0}^{\prime 2}}{2 R_{0}^{\prime \prime}}\right)\right] \times \\
\times \exp \left[i K \frac{R_{0}^{\prime}}{R_{0}^{\prime \prime}}\right] \exp \left[i \frac{K^{2}}{2 k_{0} R_{0}^{\prime \prime}}\right],
\end{gathered}
$$

where $C$ is a slowly varying function of $K$ and $k$, has necessary form, since the inverse Fourier transform over the azimuth wavenumber $K$ amounts to 


$$
\begin{gathered}
s S_{1}(x, k)=(2 \pi)^{-1} \int S S_{1}(K, k) e^{i K x} d K= \\
=C A(k) \exp \left[-i\left(k_{0}+k\right)\left(R_{0}-\frac{R_{0}^{\prime 2}}{2 R_{0}^{\prime \prime}}\right)\right] \times \\
\times \exp \left[-i \frac{k_{0} R_{0}^{\prime \prime}}{2}\left(x+\frac{R_{0}^{\prime}}{R_{0}^{\prime \prime}}\right)^{2}\right] .
\end{gathered}
$$

Introduction of $C$, which is considered constant in further calculation, is very important because it "consumes" all other constants and slowly varying terms that will appear.

The last phasor in equation (6) corresponds to the square phase error, which can be compensated easily by the multiplication of $s S_{1}(x, k)$ to the complex conjugate phasor

$$
H_{2}(x)=\exp \left[i \frac{k_{0} R_{0}^{\prime \prime}}{2} x^{2}\right]
$$

After this multiplication

$$
\begin{gathered}
s S_{2}(x, k)=s S_{1}(x, k) H_{2}(x)= \\
=C A(k) \exp \left[-i k_{0} R_{0}^{\prime} x\right] \exp \left[-i\left(k_{0}+k\right)\left(R_{0}-\frac{R_{0}^{\prime 2}}{2 R_{0}^{\prime \prime}}\right)\right] .
\end{gathered}
$$

Finally, it is necessary to calculate the Fourier transforms over $x$ and $k$ that yield

$$
S s_{2}(K, y)=C \delta\left\{K+k_{0} R_{0}^{\prime}, y-\left(R_{0}-\frac{R_{0}^{\prime 2}}{2 R_{0}^{\prime \prime}}\right)\right\},
$$

where $\delta\{\cdot, \cdot\}$ is the $2 \mathrm{D}$ delta-function.

For a stripmap SAR

$$
\begin{gathered}
R_{0} \approx y_{0}+\frac{x_{0}^{2}}{2 y_{0}} ; \\
R_{0}^{\prime}=-\frac{x_{0}}{R_{0}} ; \\
R_{0}^{\prime \prime}=\frac{y_{0}^{2}}{R_{0}^{3}} .
\end{gathered}
$$

Substitution of (9) into (8) yields

$$
S s_{2}(K, y)=C \delta\left\{K-k_{0} \frac{x_{0}}{R_{0}}, y-y_{0}\right\} .
$$

A flowchart of the synthesized algorithm is shown in Fig. 1, $a$. In Fig. $1, b$ a flowchart of the ZLZ-algorithm is depicted and its notation is adapted to the present article. Comparing the algorithms, it is easy to realize that they are almost similar. The difference is the additional multiplications of the 2D spectra $s S(x, k)$ and $S S_{2}(K, k)$ with the complex functions

$$
\begin{aligned}
& H_{0}(x, k)=\exp \left[i\left(k_{0}+k\right) \frac{R_{0}^{\prime \prime} x^{2}}{2}\right] ; \\
& H_{3}(K, k)=\exp \left[-i \frac{k K^{2}}{2 k_{0}^{2} R_{0}^{\prime \prime}}\right],
\end{aligned}
$$

in the ZLZ-algorithm. It is possible to show that these multiplications change the final 2D signal matrix to

$$
\begin{aligned}
S s_{3}(K, y)= & (2 \pi)^{-1} \int S S_{2}(K, k) H_{3}(K, k) e^{i k y} d k= \\
& =C \delta\left\{K-k_{0} \frac{x_{0}}{R_{0}}, y-R_{0}\right\} .
\end{aligned}
$$

Hence, the SAR image is constructed by this algorithm in the coordinates "along-track range - slant range". This is the difference between the algorithms, since the proposed one constructs the radar image in the "along-track range - cross-track range", which is a true Cartesian coordinate system. The synthesized algorithm has one more advantage: it requires two Hadamard matrix products less. If the received signal is a $N \times M$-matrix, where $M$ and $N$ are the numbers of the range and azimuth resolution cells correspondingly, implementation of the proposed algorithm allows to save $2 M N$ complex multiplications.

SAR imaging of moving targets. Let us consider the case when the point is uniformly moving. Suppose that its velocity is $\mathbf{U}=\hat{\mathbf{x}} U_{x}+\hat{\mathbf{y}} U_{y}$ where $\hat{\mathbf{x}}$ and $\hat{\mathbf{y}}$ are the unit vectors along the $X$ and $Y$ axes, $U_{x}$ and $U_{y}$ are the velocity projections. Then in equation (1)

$$
\begin{gathered}
R(x)=\sqrt{\left(x_{0}+u_{x} x-x\right)^{2}+\left(y_{0}+u_{y} x\right)^{2}} \approx \\
\approx R_{0}+R_{0}^{\prime} x+\frac{1}{2} R_{0}^{\prime \prime} x^{2},
\end{gathered}
$$

where $u_{x}=U_{x} / v$ and $u_{y}=U_{y} / v$; 


$$
\begin{gathered}
R_{0}=\sqrt{x_{0}^{2}+y_{0}^{2}} ; \\
R_{0}^{\prime}=\frac{1}{R_{0}}\left[\left(u_{x}-1\right) x_{0}+u_{y} y_{0}\right]= \\
=\left(u_{x}-1\right) \sin \theta_{0}+u_{y} \cos \theta_{0}=\beta ; \\
R_{0}^{\prime \prime}=\frac{1}{R_{0}^{3}}\left[\left(u_{x}-1\right) y_{0}-u_{y} x_{0}\right]^{2}= \\
=\frac{1}{R_{0}}\left[\left(u_{x}-1\right) \cos \theta_{0}-u_{y} \sin \theta_{0}\right]^{2}=\frac{\gamma^{2}}{R_{0}},
\end{gathered}
$$

$\theta_{0}$ is the line of sight angle of the point. In equation

(10) new variables $\beta=\left(u_{x}-1\right) \sin \theta_{0}+u_{y} \cos \theta_{0}$ and $\gamma=\left(u_{x}-1\right) \cos \theta_{0}-u_{y} \sin \theta_{0}$ are introduced. Physical meaning of the introduced parameters is obvious: $\beta$ and $\gamma$ are the radial and transverse normalized speeds of the target relatively to the radar.

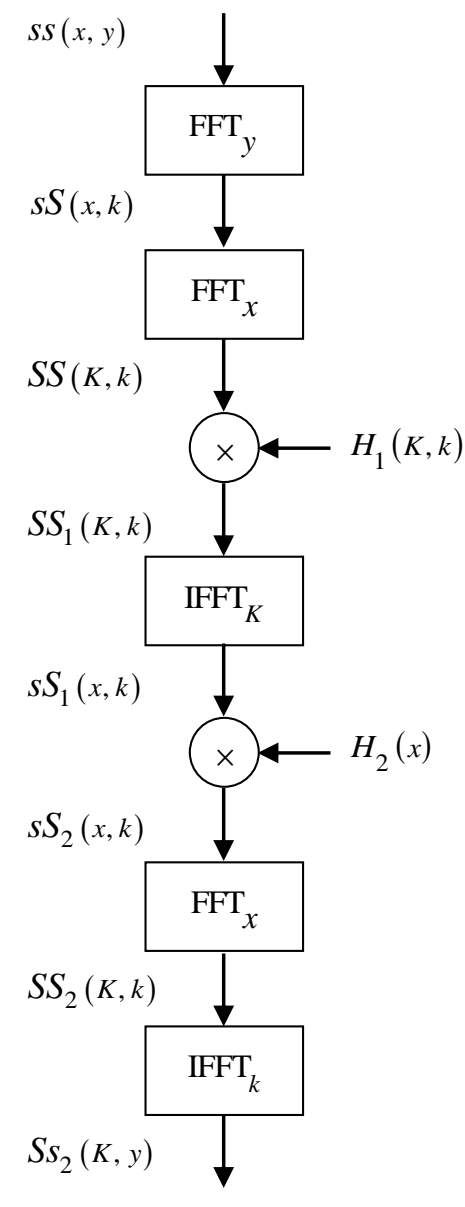

$a$
Then equation (3) can be rewritten as,

$$
\begin{gathered}
s S(x, k)=A(k) e^{-i\left(k_{0}+k\right) R_{0}} \times \\
\times \exp \left[-i\left(k_{0}+k\right)\left(\beta x+\frac{\gamma^{2}}{2 R_{0}} x^{2}\right)\right] .
\end{gathered}
$$

Let us apply the designed algorithm starting from the step, which corresponds to the calculation of the spectrum $S S(K, k)$. In further computations it is supposed that the stationary phase method (see, e. g. [26]) can be applied the perform necessary integrations.

The Fourier transformation over the variable $x$ in (11) yields

$$
\begin{gathered}
S S(K, k)=C \exp \left[-i\left(k_{0}+k\right) R_{0}\left(1-\frac{\beta^{2}}{2 \gamma^{2}}\right)\right] \times \\
\quad \times \exp \left[i \frac{\beta K R_{0}}{\gamma^{2}}\right] \exp \left[i \frac{K^{2} R_{0}}{2 \gamma^{2}\left(k_{0}+k\right)}\right] .
\end{gathered}
$$

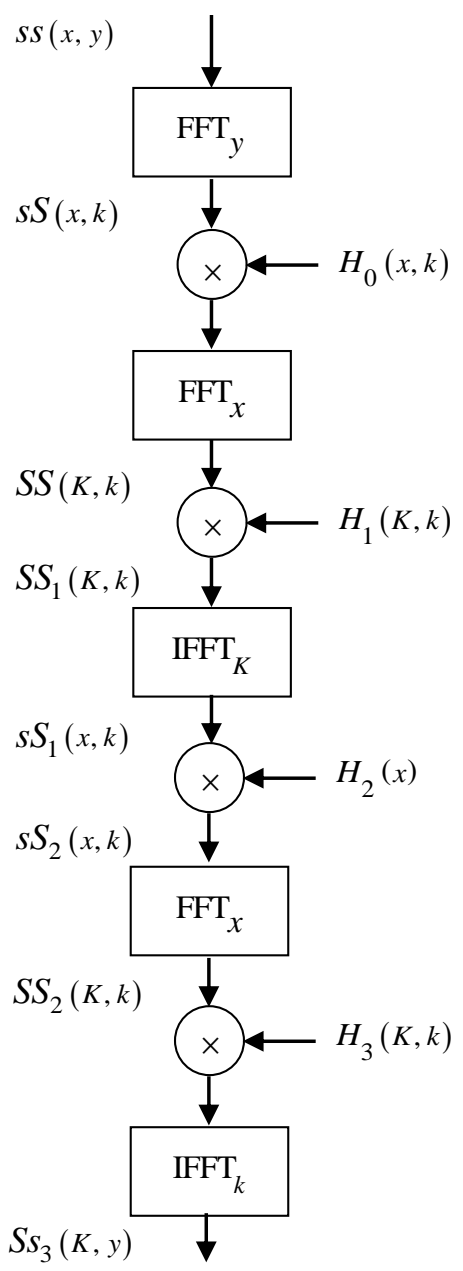

$b$

Fig. 1. Flowcharts of the algorithms: $a$ - the ZLZ-algorithm; $b$ - the proposed algorithm 
After multiplication of $S S(K, k)$ to $H_{1}(K, k)$ of

(5) the spectrum $S S_{1}(K, k)$ can be written as,

$$
\begin{gathered}
S S_{1}(K, k)=C \exp \left[-i\left(k_{0}+k\right) R_{0}\left(1-\frac{\beta^{2}}{2 \gamma^{2}}\right)\right] \times \\
\quad \times \exp \left[i \frac{\beta K R_{0}}{\gamma^{2}}\right] \exp \left[i \frac{K^{2} R_{0}\left(k_{0}+\gamma^{2} k\right)}{2 \gamma^{2} k_{0}\left(k_{0}+k\right)}\right] .
\end{gathered}
$$

The inverse Fourier transformation of $S S_{1}(K, k)$ over the azimuth wavenumber $K$ produces

$$
\begin{gathered}
s S_{1}(x, k)=C \exp \left[-i\left(k_{0}+k\right) R_{0}\left(1-\frac{\beta^{2}}{2 \gamma^{2}}\right)\right] \times \\
\times \exp \left[-i \frac{\gamma^{2} k_{0}\left(k_{0}+k\right)}{2 R_{0}\left(k_{0}+\gamma^{2} k\right)}\left(x+\frac{\beta R_{0}}{\gamma^{2}}\right)^{2}\right] .
\end{gathered}
$$

Multiplying $s S_{1}(x, k)$ with $H_{2}(x)$ of (7) and performing some simplifications, the following equation can be received:

$$
\begin{aligned}
& s S_{2}(x, k)=C \exp \left[-i\left(k_{0}+k\right) R_{0}\left(1-\frac{\beta^{2}}{2 \gamma^{2}}\right)\right] \times \\
& \times \exp \left[-i \frac{\gamma^{2} k_{0}\left(k_{0}+k\right)}{2 R_{0}\left(k_{0}+\gamma^{2} k\right)}\left(x+\frac{\beta R_{0}}{\gamma^{2}}\right)^{2}+i \frac{k_{0} x^{2}}{2 R_{0}}\right] .
\end{aligned}
$$

Then

$$
\begin{gathered}
S S_{2}(K, k)=C \exp \left[-i \frac{K^{2} R_{0}}{2 k_{0}}\right] \times \\
\times \exp \left\{-i\left(k_{0}+k\right) R_{0}\left[1-\frac{\beta^{2}}{2 \gamma^{2}}+\frac{1}{2\left(1-\gamma^{2}\right)}\left(\frac{\gamma K}{k_{0}}+\frac{\beta}{\gamma}\right)^{2}\right]\right\} .
\end{gathered}
$$

Finally, performing the inverse Fourier transformation over the range wavenumber $k$ we have

$$
\begin{gathered}
S s_{2}(K, y)=C e^{-i k_{0} y} \exp \left[-i \frac{K^{2} R_{0}}{2 k_{0}}\right] \times \\
\times \delta\left\{y-R_{0}\left[1-\frac{\beta^{2}}{2 \gamma^{2}}+\frac{1}{2\left(1-\gamma^{2}\right)}\left(\frac{\gamma K}{k_{0}}+\frac{\beta}{\gamma}\right)^{2}\right]\right\},
\end{gathered}
$$

where $\delta\{\cdot\}$ is the Dirac delta-function. The function $S s_{2}(K, y)$ should be considered as a distribution (generalized function), i. e. a linear functional over the space $D\left(\mathbb{R}^{2}\right)$ of infinitely differentiable complexvalued functions with compact support [27]. Suppose an arbitrary function $\varphi(K, y) \in D\left(\mathbb{R}^{2}\right)$ and let us calculate the scalar product

$$
\left\langle S s_{2}, \varphi\right\rangle=\int_{\mathbb{R}^{2}} S s_{2}(K, y) \varphi(K, y) d K d y .
$$

To perform the calculation, it necessary to do integration in (12) sequentially over $y$ and $K$ variables. Integration over $y$ is very easy

$$
\begin{gathered}
=C \int_{\mathbb{R}} d K \varphi\left\{K, R_{0}\left[1-\frac{\beta^{2}}{2 \gamma^{2}}+\frac{1}{2\left(1-\gamma^{2}\right)}\left(\frac{\gamma K}{k_{0}}+\frac{\beta}{\gamma}\right)^{2}\right]\right\} \times \\
\times \exp \left[-i \frac{K^{2} R_{0}}{2 k_{0}}\right] \times \\
\times \exp _{\{}\left\{-i k_{0} R_{0}\left[1-\frac{\beta^{2}}{2 \gamma^{2}}+\frac{1}{2\left(1-\gamma^{2}\right)}\left(\frac{\gamma K}{k_{0}}+\frac{\beta}{\gamma}\right)^{2}\right]\right\}= \\
=C \int_{\mathbb{R}} \int_{\mathbb{R}} d K \varphi\left\{K, R_{0}\left[1-\frac{\beta^{2}}{2 \gamma^{2}}+\frac{1}{2\left(1-\gamma^{2}\right)}\left(\frac{\gamma K}{k_{0}}+\frac{\beta}{\gamma}\right)^{2}\right]\right\} \times \\
\quad \times \exp \left\{-i k_{0} R_{0}\left[1+\frac{1}{2\left(1-\gamma^{2}\right)}\left(\frac{K}{k_{0}}+\beta\right)^{2}\right]\right\} .
\end{gathered}
$$

The second integration over $K$ can be done by the stationary phase method

$$
\left\langle S s_{2}, \varphi\right\rangle=C \varphi\left\{-\beta k_{0}, R_{0}\left(1-\frac{1}{2} \beta^{2}\right)\right\} .
$$

Since the function $\varphi\{K, y\}$ is chosen arbitrary it can be argued that

$$
S_{2}(K, y) \propto \delta\left\{K+k_{0} \beta, y-R_{0}\left(1-\frac{\beta^{2}}{2}\right)\right\},
$$

where $\propto$ designates the equivalence. It means that the function $S_{2}(K, y)$ belongs to the same equivalence class in $L_{2}$ functional space that contains the Dirac delta-function standing in the right hand side of (13). Hence, the image of a moving target is concentrated in the point with coordinates $\left[-k_{0} \beta, R_{0}\left(1-0.5 \beta^{2}\right)\right]$. For a stationary target equation (13) coincides with equation (8). Since the azimuth wavenumber 


$$
K=\frac{k_{0} x}{R_{0}},
$$

where $x$ is the cross-track range, the image position is $\left[\hat{x}_{0}=-\beta R_{0}, \hat{y}_{0}=R_{0}\left(1-0.5 \beta^{2}\right)\right]$. Therefore, in case of a moving target its image is shifted from the true position. The shift depends on the relative projection of the target velocity on the line-of-sight.

Analysis in this section shows that the proposed algorithm produces the well-focused image of a moving target if the CPI is infinitely large. In case of a finite CPI, as it is shown in the next section, the image looks like a crossing of two ridges. One ridge is parallel to the $y$ axis, the other one is inclined to the $x$ axis. The focused image lays along the second ridge. It is possible to show that this ridge approximately lies along the line

$$
\begin{gathered}
y=R_{0}\left(1-\frac{\beta^{2}}{2}\right)+\beta\left(x+\beta R_{0}\right)+\frac{\gamma^{2}\left(x+\beta R_{0}\right)^{2}}{2 R_{0}\left(1-\gamma^{2}\right)}= \\
=\hat{y}_{0}+\beta\left(x-\hat{x}_{0}\right)+\frac{\gamma^{2}\left(x-\hat{x}_{0}\right)^{2}}{2 R_{0}\left(1-\gamma^{2}\right)} .
\end{gathered}
$$

The line passes the point $\left[\hat{x}_{0}, \hat{y}_{0}\right]$ and the tangent of its inclination angle is $\tan \psi=\beta$. Therefore, estimating the three parameters $\hat{x}_{0}, \hat{y}_{0}, \tan \psi$ directly from the image it is possible to determine the three a priory unknown movement parameters $\theta_{0}, U_{x}, U_{y}$ of the target.

Similar analysis can be performed for the ZLZalgorithm. It is possible to show that in this case

$$
\begin{gathered}
S s_{3}(K, y)= \\
=C e^{-i k_{0} y} \delta\left\{y-R_{0}\left[1+\frac{1}{2(2-\gamma)}\left(\frac{K}{k_{0}}+\beta\right)^{2}\right]\right\} .
\end{gathered}
$$

Treating $\mathrm{Ss}_{3}(K, y)$ as a distribution it is straightforward to show that

$$
S s_{3}(K, y) \propto \delta\left\{K+\beta k_{0}, y-R_{0}\right\} .
$$

Hence, if the CPI is infinitely large the image produced by the ZLZ-algorithm is well focused too and its position is $\left[\hat{x}_{0}=-\beta R_{0}, \hat{y}_{0}=R_{0}\right]$. When the $\mathrm{CPI}$ is finite the image lays along the line

$$
y=R_{0}+\frac{\left(x+\beta R_{0}\right)^{2}}{2(2-\gamma) R_{0}} .
$$

This is a parabola passing through the point $\left[\hat{x}_{0}, \hat{y}_{0}\right]$ and the tangent of its inclination angle is $\tan \psi=0$. Estimation of the moving parameters in this case is more difficult.

Results of the computer simulation. Computer simulation of the synthesized algorithm was executed with the following scenario parameters:

- wavelength $\lambda=5.6 \mathrm{~cm}$;

- real antenna aperture length $L=1 \mathrm{~m}$;

- pulse bandwidth $\Delta F=200 \mathrm{MHz}$;

- vehicle speed $v=40 \mathrm{~m} / \mathrm{s}$;

- distance to the nearest image border $y_{b}=10 \mathrm{~km}$;

- length of the synthesized aperture $D=410 \mathrm{~m}$;

- number of range resolution cells $M=512$;

- number of azimuth resolution cells $N=4096$.

The simulation results are presented in Fig. 2. Fig. 2, $a$ shows the image contours of a point with coordinates $x_{0}=529 \mathrm{~m}$ and $y_{0}=10086 \mathrm{~m}\left(R_{0}=10100 \mathrm{~m}\right)$ obtained by the standard SAR algorithm [1], which includes sequential execution of the matched filtering of the received signal at each repetition period, quadratic term compensation and harmonic signal analysis using the Fast Fourier Transform over the "slow" time $t$. From the figure it follows that signal compression is not effective. The radar image of the source is "smeared" in the along-track and the cross-track ranges.

Fig. 2, $b$ shows similar contours for the synthesized algorithm and Fig. 2, $c$ for the ZLZ-algorithm. Simultaneous compression of the image along the along-track and cross-track ranges is observed and the quality of the radar images are similar. At the same time the point image for the proposed algorithm has the true Cartesian coordinates $\left(x_{0}, y_{0}\right)$. The ZLZalgorithm focused the image in the point $\left(x_{0}, y_{0}\right)$, as it was indicated above. Thus, the simulation proves the efficiency of the synthesized algorithm in case of stationary targets.

In Fig. 3 there are similar radar images for a moving target with the velocity $\mathbf{U}=4.4 \mathrm{~m} / \mathrm{s}$. 
Известия вузов России. Радиоэлектроника. 2021. Т. 24, № 2. С. 27-37 Journal of the Russian Universities. Radioelectronics. 2021, vol. 24, no. 2, pp. 27-37

Quality of the radar image of the standard SAR algorithm (Fig. 3, $a$ ) deteriorates significantly in comparison with the image in Fig. 2, $a$ : it is much more blurred and shifted from the true target position. Qualities of the images of the proposed algorithm (Fig. 3, b) and the ZLZ-algorithm (Fig. 3,c) are much better. They are slightly "smeared" and shifted, as it was predicted in the previous section. It is worth to note that the shape of the target image of the ZLZ-algorithm lays along the dashed magenta line that corresponds to the parabola (15) and the envelope of the image is parallel to the axis $x$. At the same time the image of the proposed algorithm changes its shape: the ridge that was parallel to the axis $x$ in Fig. 2, $b$ has changed its inclination and lays along the dashed magenta line, which equation is (14). This inclination can be used to estimate the target radial speed although such estimation can be realized via implementation of complicate algorithms using the Wigner-Ville Distribution [28, 29], the Fractional Fourier Transform [30, 31] or the Radon Transform [32, 33]. These algorithm permit to estimate the transverse target speed, as well. Estimating of the image position $\left[\hat{x}_{0}, \hat{y}_{0}\right]$ and parameters $\beta$ and $\gamma$ it is possible to determine the initial coordinates and the velocity of the target.

Conclusion. The range cell migrations (RCM) is one of the main factors that deteriorates the quality of SAR images. The article synthesizes an RCM compensation algorithm without interpolation. The synthe-
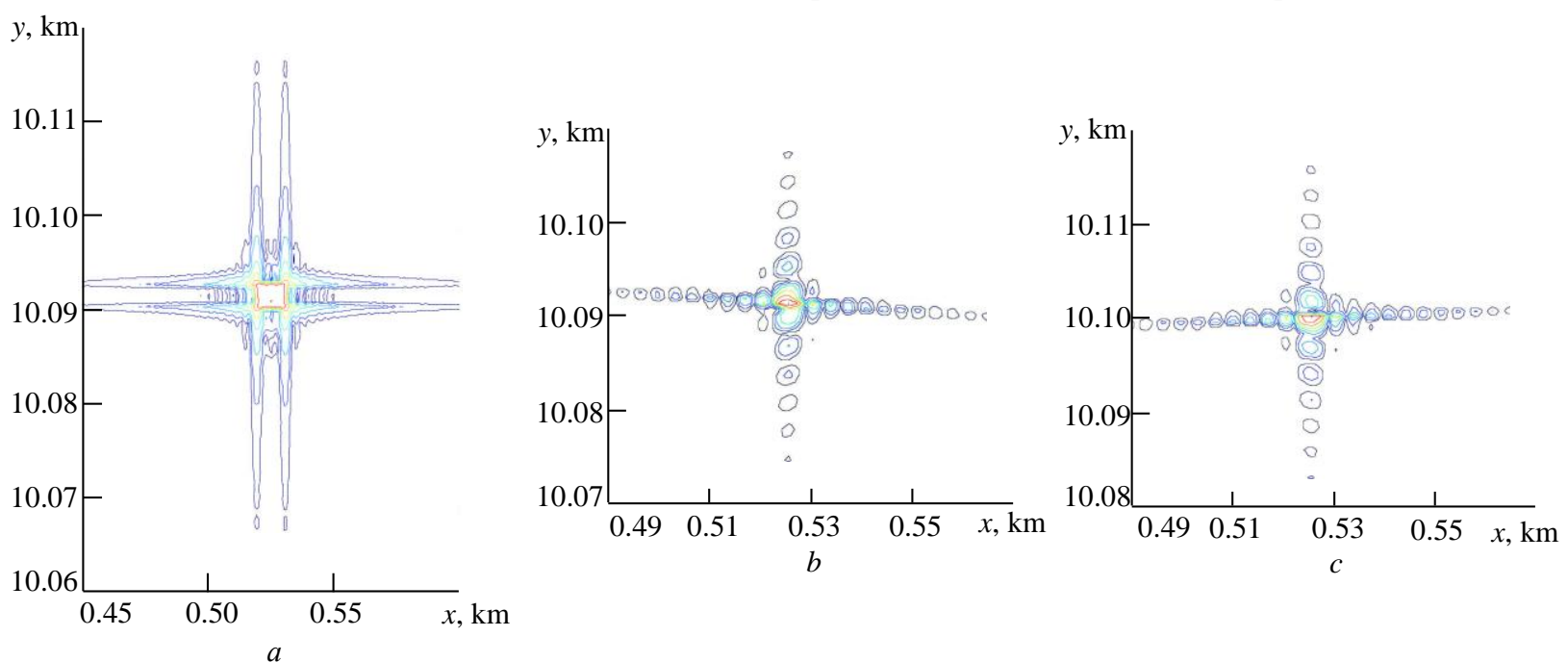

Puc. 2. Results of the simulation: SAR images of a stationary target: $a$ - standard algorithm; $b$ - synthesized algorithm; $c$ - ZLZ-algorithm

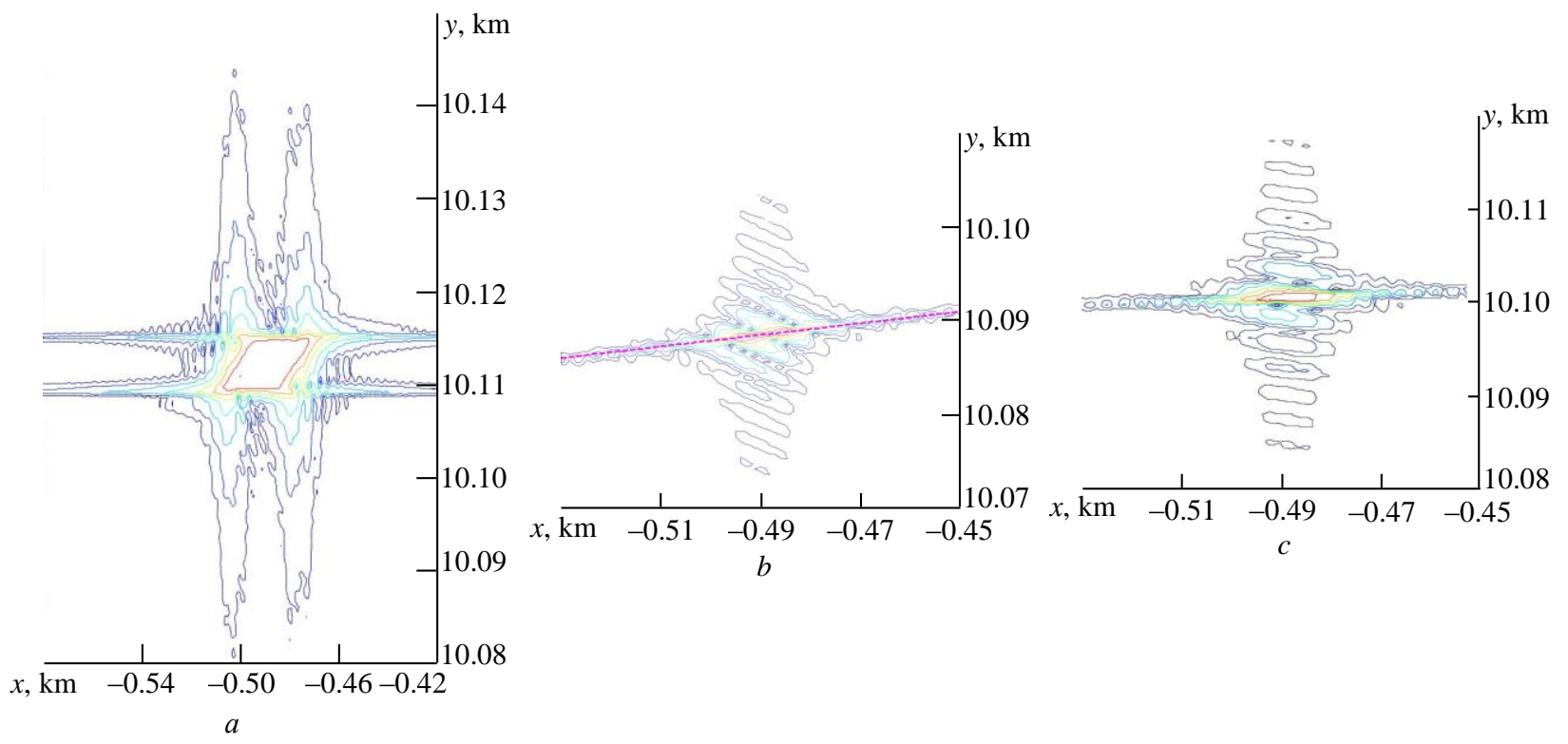

Puc. 3. Results of the simulation: SAR images of a moving target: $a$ - standard algorithm; $b$ - synthesized algorithm; $c$-ZLZ-algorithm 
Известия вузов России. Радиоэлектроника. 2021. Т. 24, № 2. С. 27-37

Journal of the Russian Universities. Radioelectronics. 2021, vol. 24, no. 2, pp. 27-37

sized algorithm is a new variant of the Keystone Transform algorithm without interpolation. The basis of the proposed algorithm are the reduced Chirp Scaling and the Fast Fourier Transforms. The proposed algorithm is simpler than the Keystone Transform. It does not need any functional interpolation and yields the radar image in the true Cartesian "along-track range - crosstrack range" coordinates. Computer simulation proves high efficiency of the algorithm. The proposed algo- rithm can be used for SAR imaging of moving targets. In this case the algorithm would produce a focused image of the moving target that is shifted from the target true position and slightly rotated. The shift and the inclination angle of the image depend on the projection of the target relative velocity on the line-of-sight, i. e. the radial speed of the target. Estimation of the image parameters permits to determine the target movement parameters - its true position and velocity.

\section{References}

1. Moreira A., Prats-Iraola P., Younis M., Krieger G., Hajnsek I., Papathanassiou K. P. A tutorial on synthetic aperture radar, IEEE Geoscience and Remote Sensing Magazine. Mar. 2013, vol. 1, iss. 1, pp. 6-43. doi: 10.1109/MGRS.2013.2248301

2. Uysal F. Comparison of range migration correction algorithms for range-Doppler processing. J. Appl. Remote Sens. 2017, vol. 11, iss. 3, art. 036023, pp. 1-10. doi: 10.1117/1.JRS.11.036023

3. Cumming I., Bennett J. Digital processing of Seasat SAR data. Proc. Article in ICASSP' 79. IEEE Intern. Conf. on Acoustics, Speech and Signal Proc. Apr. 1979, vol. 4, pp. 710-718. doi: 10.1109/icassp.1979.1170630

4. Jin M. Y., Wu C. A SAR correlation algorithm which accommodates large range migration. IEEE Transactions on Geoscience and Remote Sensing. Nov. 1984, vol. GE22, iss. 6, pp. 592-597. doi: 10.1109/tgrs.1984.6499176

5. Chang C. Y., Jin M., Curlander J. C. Squint Mode SAR Processing Algorithms in 12th Canadian Symp. on Remote Sensing Geoscience and Remote Sensing Symp. Jul. 1989, vol. 3, pp. 1702-1706. doi: 10.1109/igarss.1989.576456

6. Smith A. M. A new approach to range-Doppler SAR processing. Intern. J. of Remote Sensing. Feb. 1991, vol. 12, iss. 2, pp. 235-251. doi: 10.1080/01431169108929650

7. Franceschetti G., Schirinzi G., A SAR processor based on two-dimensional FFT code. IEEE Transactions on Aerospace Electronic Systems. Mar. 1990, vol. 26, iss. 2, pp. 356-366. doi: 10.1109/7.53462

8. Cafforio C., Prati C., Rocca F. SAR data focusing using seismic migration techniques. IEEE Transactions on Aerospace and Electronic Systems. Mar. 1991, vol. 27, iss. 2, no. 2, pp. 194-207. doi: 10.1109/7.78293

9. Franceschetti G., Lanari R., Marzouk E. S. Aberration free SAR raw data processing via transformed grid predeformation. Proc. of IGARSS '93 - IEEE Intern. Geoscience and Remote Sensing Symp. Aug. 1993, vol. 4, pp. 1593-1595. doi: 10.1109/igarss.1993.322306

10. Stolt R. H. Migration by Fourier transform. Geophysics. Feb. 1978, vol. 43, iss. 1, pp. 23-48. doi: 10.1190/1.1440826

11. Perry R. P., DiPietro R. C., Fante R. L. SAR imaging of moving targets. IEEE Transactions on Aerospace Electronic Systems. Jan. 1999, vol. 35, iss. 1, pp. 188-200. doi: $10.1109 / 7.745691$
12. Perry R. P., DiPietro R. C., Fante R. L. Coherent Integration with Range Migration Using Keystone Formatting. 2007 IEEE Radar Conf. Apr. 2007, pp. 863-868. doi: 10.1109/radar.2007.374333

13. Runge H., Bamler R. A Novel High Precision SAR Focussing Algorithm Based on Chirp Scaling. Proc. Article IGARSS ' 92 Intern. Geoscience and Remote Sensing Symp. May 1992, vol. 1, pp. 372-375. doi: 10.1109/igarss.1992.576715

14. Cumming I., Wong F., Raney K. A SAR Processing Algorithm with no Interpolation. Proc. IGARSS '92 Intern. Geoscience and Remote Sensing Symp. May 1992, vol. 1, pp. 376-379. doi: 10.1109/igarss.1992.576716

15. Wong F., Cumming I., Raney R. K. Processing simulated RADARSAT SAR data with squint by a high precision algorithm. Proc. of IGARSS '93. IEEE Intern. Geoscience and Remote Sensing Symp. Aug. 1993, vol. 3, pp. 11761178. doi: 10.1109/igarss.1993.322127

16. Raney R. K., Runge H., Bamler R., Cumming I. G., Wong F. H. Precision SAR processing using chirp scaling. IEEE Transactions on Geoscience and Remote Sensing. Jul. 1994, vol. 32, iss. 4, pp. 786-799. doi: 10.1109/36.298008

17. Moreira A., Huang Y. Airbome SAR Processing of Highly Squinted Data Using a Chirp Scaling Approach with Integrated Motion Compensation. IEEE Trans. Geoscience and Remote Sensing. 1994, vol. 32, iss. 5, pp. 1029-1040. doi: 10.1109/36.312891

18. Moreira A., Mittermayer J., Scheiber R. Extended chirp scaling algorithm for air- and spaceborne SAR data processing in stripmap and scanSAR imaging modes. IEEE Transactions on Geoscience and Remote Sensing. J. Article. 1996, vol. 34, iss. 5, pp. 1123-1136. doi: $10.1109 / 36.536528$

19. Mittermayer J., Moreira A., Loffeld O. Spotlight SAR data processing using the frequency scaling algorithm. IEEE Transactions on Geoscience and Remote Sensing. Sep. 1999, vol. 37, iss. 5, pp. 2198-2214. doi: 10.1109/36.789617

20. Zhu D., Shen M., Zhu Z. Some Aspects of Improving the Frequency Scaling Algorithm for Dechirped SAR Data Processing. IEEE Transactions on Geoscience and Remote Sensing. 2008, vol. 46, iss. 6, pp. 1579-1588. doi: $10.1109 /$ tgrs.2008.916468 
Известия вузов России. Радиоэлектроника. 2021. Т. 24, № 2. С. 27-37 Journal of the Russian Universities. Radioelectronics. 2021, vol. 24, no. 2, pp. 27-37

21. Zhou F., Wu R., Xing M., Bao Z. Approach for single channel SAR ground moving target imaging and motion parameter estimation. IET Radar, Sonar\&amp, Navigation. 2007, vol. 1, no. 1, pp. 59-66. doi: 10.1049/iet-rsn:20060040

22. Scott K. M., Barott W. C., Himed B. The keystone transform: Practical limits and extension to second order corrections. IEEE Radar Conf. (RadarCon), Arlington, VA. 2015, pp. 1264-1269. doi: 10.1109/RADAR.2015.7131189

23. Zhu D., Li Y., Zhu Z. A Keystone Transform without Interpolation for SAR Ground Moving Target Imaging. IEEE Geoscience and Remote Sensing Lett. 2007, vol. 4, iss. 1, pp. 18-22. doi: 10.1109/lgrs.2006.882147

24. Papoulis A. The Fourier integral and its applications. New York, McGraw-Hill, 1962.

25. Monakov A. An algorithm of range migration compensation for sidelooking SAR. Electromagnetic waves and electronic systems. 2018, vol. 23, no. 7, pp. 6-12. doi: 10.18127/j15604128-201807-02 (In Russ.)

26. Fedoryuk M. V. Asymptotic: Integrals and Series. Moscow, Nauka, 1987, 366 p. (In Russ.)

27. Vladimirov V. S. Generalized functions in mathematical physics. Moscow, Nauka, 1979, 320 p. (In Russ.)

28. Barbarossa S., Farina A. Detection and imaging of moving objects with synthetic aperture radar. Pt. 2. Joint time-frequency analysis by Wigner Ville distribution. IEE
Proceedings F (Radar and Signal Processing). 1992, vol. 139, no. 1, pp. 89-97. doi: 10.1049/ip-f-2.1992.0011

29. Barbarossa S. Analysis of multicomponent LFM signals by a combined Wigner-Hough transform. IEEE Transactions on Signal Processing. 1995, vol. 43, no. 6, pp. 1511-1515. doi: 10.1109/78.388866

30. Hong-Bo Sun, Guo-Sui Liu, Hong Gu, Wei-Min Su Application of the fractional Fourier transform to moving target detection in airborne SAR, IEEE Transactions on Aerospace and Electronic Systems. 2002, vol. 38, no. 4, pp. 1416-1424. doi: 10.1109/TAES.2002.1145767

31. Yu X., Chen X., Huang Y., Guan J. Sparse Fractional Fourier Transform and its Applications in Radar Moving Target Detection, Intern. Conf. on Radar (RADAR), Bris-bane, QLD. 2018, pp. 1-5. doi: 10.1109/RADAR.2018.8557319

32. Sharif M. R., Abeysekera S. S. Efficient wideband signal parameter estimation using a Radon-ambiguity transform slice, IEEE Transactions on Aerospace and Electronic Systems. 2007, vol. 43, no. 2, pp. 673-688. doi: 10.1109/TAES.2007.4285361

33. Yang J., Zhang Y. A novel keystone transform based algorithm for moving target imaging with Radon transform and fractional Fourier transform involved, Progress in Electromagnetics Research Symposium. 2014, pp. $1406-1410$.

\section{Information about the author}

Andrey A. Monakov, Dr. Sci. (Eng.) (2000), Professor (2005) of the Department of radio equipment systems of the Saint Petersburg State University of Aerospace Instrumentation, Honorable Mechanical Engineer of the Russian Federation (2005), Honorable Worker of Higher Professional Education of the Russian Federation (2006). The author of more than 150 scientific publications. Area of expertise: digital signal processing; radar theory; microwave remote sensing; air traffic control.

Address: Institute of Radio Engineering, Electronics and Communications, Saint Petersburg State University of Aerospace Instrumentation, 67A Bolshaja Morskaja St., St Petersburg 190121, Russia

E-mail: a_monakov@mail.ru

https://orcid.org/0000-0003-4469-0501 